\title{
Cutting Force Simulation of Titanium based on DEFORM-3D
}

\author{
CHEN Zhuo ${ }^{1, a}$, QIN Lu-fang ${ }^{1, \text { b* }}$ and YANG Li-juan ${ }^{3, c}$ \\ ${ }^{1}$ Jiangsu Key Laboratory of Large Engineering Equipment Detection and Control, Xuzhou Institute \\ of Technology, Xuzhou, 221000, Jiangsu, China

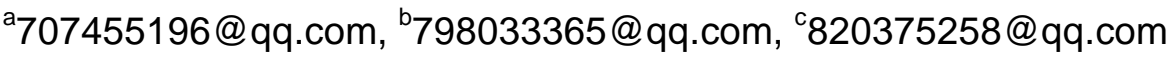

Keywords: Cutting force simulation; Titanium; DEFORM-3D; Finite element method Abstract. DEFORM-3D is a finite element method (FEM) software that can perfectly simulate cutting process of materials. In order to research the cutting process of titanium, using DEFORM-3D software as a platform, through FEM on modeling and simulation to the cutting of TC4, the influence rule of cutting depth on cutting force was got with analysis. In addition, cutting force experiment was carried out to validate the accuracy of DEFORM-3D simulation. The results of research show that predicted cutting force values of DEFORM-3D has good accuracy.

\section{Introduction}

Finite element method (FEM) was applied in machining more than thirty years ago. FEM has made tremendous achievements from simple two-dimensional orthogonal cutting simulation analysis in the beginning to three-dimensional orthogonal cutting and oblique cutting simulation at now, and from simple parameters setting to multiple parameters setting, etc[1-3].

Actual cutting process occurs in three-dimensional deformation area. For example, tool and workpiece have geometrical shapes with three-dimensional, relative movement between tool and workpiece is not always orthogonal, some workpiece materials are anisotropic and so on. With the improvement of the computing capacity of hardware, the three-dimensional cutting simulation is primary direction to further study cutting mechanism[4-6].

In recent years, some softwares are developed for simulation of cutting process such as ANSYS, DEFORM, ABAQUS, etc. DEFORM-3D is a finite element simulation software based on process simulation system that synthesizes functions for modeling, shaping, heat conducting, forming equipment and so on. DEFORM-3D has some features such as good robustness, easy to use, powerful simulation engine, etc.

In this paper, DEFORM-3D is used to research cutting force simulation of turning for Titanium TC4. In addition, cutting force experiments are adopted to validate the accuracy of simulation. Through the research, some directions and help can be provided to expand application range DEFORM-3D and reduce experimental times.

\section{Experiment Process}

Parameters Setting of Simulation. The cutting forces under different cutting depth are simulated and researched. The parameters of simulation and material properties are respectively shown in table 1 and 2.

Table1 Experimental parameters of high speed turning

\begin{tabular}{|c|c|}
\hline cutting speed $v(\mathrm{~m} / \mathrm{min})$ & 40 \\
\hline cutting depth $a_{p}(\mathrm{~mm})$ & $0.3,0.4,0.5,0.6,0.7$ \\
\hline feed $f(\mathrm{~mm} / \mathrm{r})$ & 0.3 \\
\hline
\end{tabular}


Table2 Main physical and mechanical properties of experimental materials TC4

\begin{tabular}{|c|c|c|c|c|}
\hline $\begin{array}{c}\text { tensile strength } \\
\sigma_{b}(\mathrm{MPa})\end{array}$ & $\begin{array}{c}\text { yield strength } \\
\sigma_{0.2}(\mathrm{MPa})\end{array}$ & $\begin{array}{c}\text { elongation } \\
\delta_{5}(\%)\end{array}$ & $\begin{array}{c}\text { percentage of area } \\
\text { reduction } \psi(\%)\end{array}$ & $\begin{array}{c}\text { impact toughness } \\
a_{K U}\left(\mathrm{~J} / \mathrm{cm}^{2}\right)\end{array}$ \\
\hline 903 & 825 & 16.8 & 42.8 & 46 \\
\hline
\end{tabular}

Establishment of Cutting Model. Cutting deformed processes of material were usually identified as plastic strain. Johnson-Cook constitutive model were widely used for material flow stress model of cutting simulation, as follows.

$$
\bar{\sigma}=\left(A+B \varepsilon^{n}\right) \cdot\left(1+C \ln \frac{\varepsilon \&}{\varepsilon_{0}}\right) \cdot\left[1-\left(\frac{T-T_{r}}{T_{m}-T_{r}}\right)^{m}\right]
$$

Where $A, B, n, C$ and $m$ are self-determining constants of material. $T_{m}$ is melting point of material and $T_{r}$ is room temperature . $\varepsilon_{0}$ is strain rate of reference. The first part of right equation is expressed as the extent of flow stress $\bar{\sigma}$ impact of the strain $\varepsilon$, the second part as the extent of $\bar{\sigma}$ impact of the strain rate $\& \& \varepsilon_{0}$, the final part as the extent of $\bar{\sigma}$ impact of temperature $T$.

In this paper, adopted $\mathrm{J}-\mathrm{C}$ model is as shown.

$$
\bar{\sigma}=\left(968.88+567.17 \varepsilon^{0.375}\right) \cdot\left(1+0.0394 \ln \frac{\& \&}{\varepsilon_{0}}\right) \cdot\left[1-\left(\frac{T-T_{r}}{T_{m}-T_{r}}\right)^{1.30}\right]
$$

Setting of Geometry Model and Simulation. Turning module is selected to model turning process, as shown in figure 1 and 2. For mesh partition of workpiece, absolute mesh is adopted and maximum-minimum mesh size ratio is seven. For grid partition of tool, relative mesh is adopted and amounts of mesh is 40,000 .



Fig. 1 Settings Screen of workpiece shape

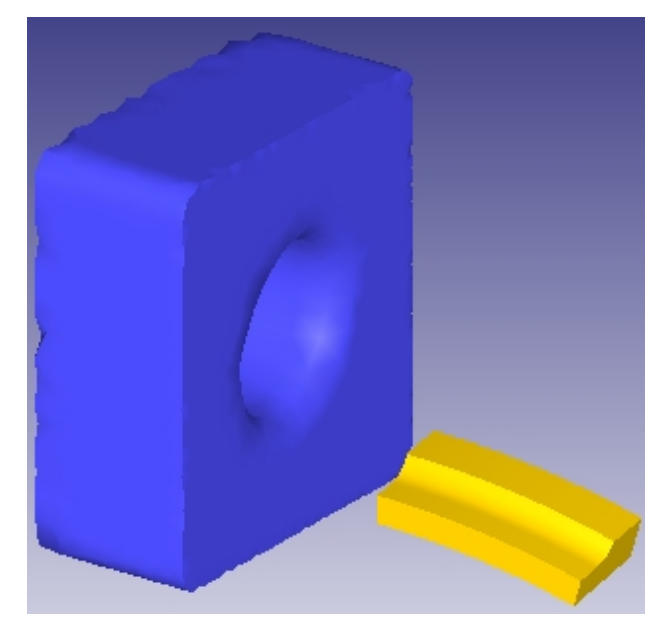

Fig. 2 Sketch of cutting model

\section{Results and Analysis}

Cutting force is an important parameter in cutting process that has a great influence on cutting temperature, tool life, machining precision, etc. Figure 3 shows stress states of cutting process. From this figures, we can find that distribution of stress is very complex. In beginning stage of cutting, maximum equivalent stress of deformed workpiece occurred in tip of cutting edge. In process of cutting, the area of maximum equivalent stress was gradually expanding. After breaking through shear zone, the equivalent stress in tip of cutting edge decreased to some extent and decreased region gradually obliquely extend to all shear zone.

The cutting forces under different cutting depth were simulated, as shown figure 4 . From figure 4, we can find that primary cutting force is main influence factor in cutting process, and other cutting forces is relatively small. In cutting force process, cutting force include two parts, static and dynamic component. Static component is average of cutting force and dynamic component oscillate around 
average of cutting force. Above discussion and results reflect the validity of DEFORM-3D simulation in cutting process.

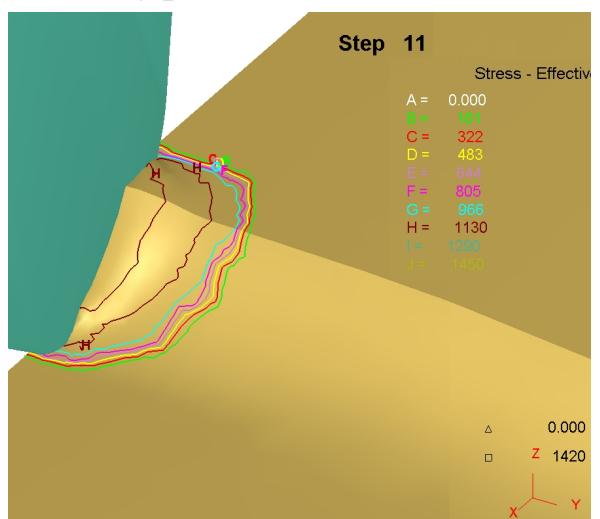

(a) Beginning stage of cutting

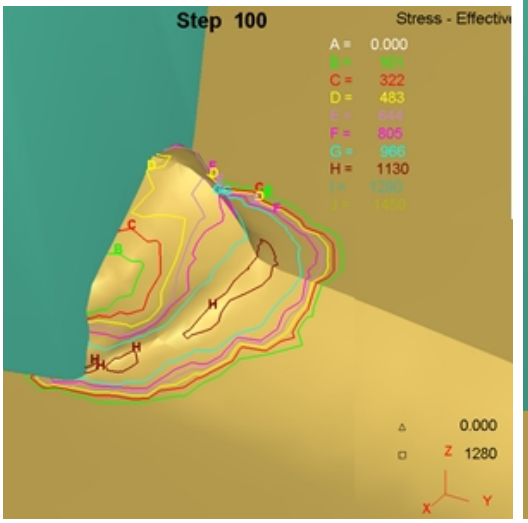

(b) Process of cutting

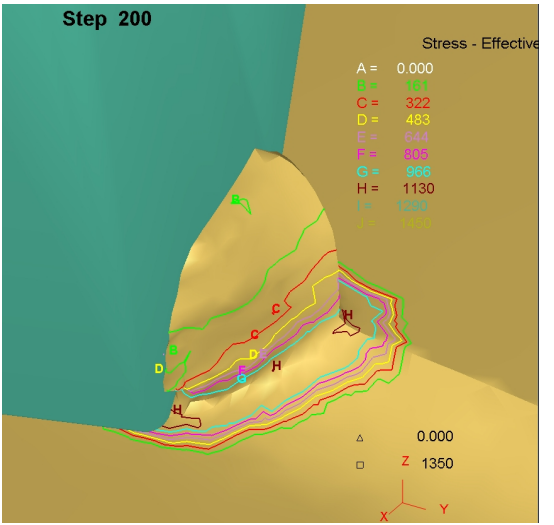

(c) Breaking through shear zone

Fig. 3 Stress contour in the front of cutting edge

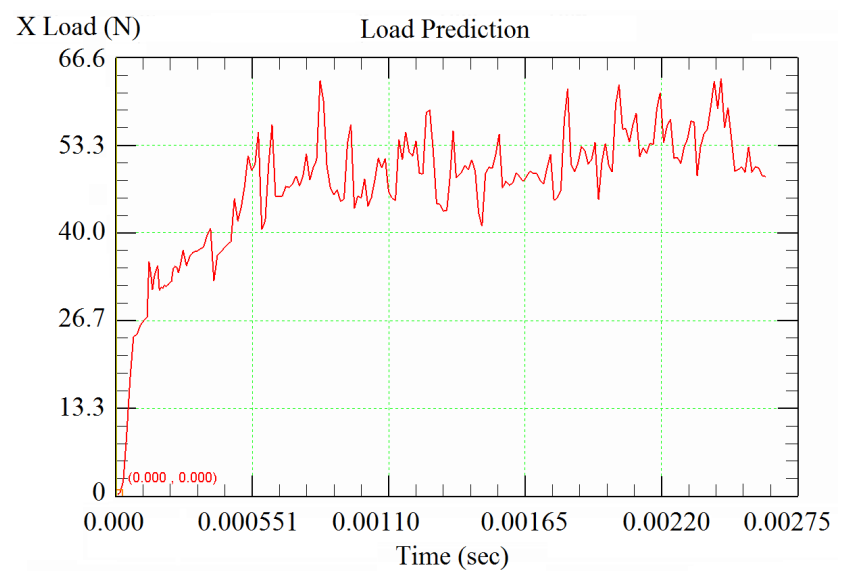

(a) Primary cutting force

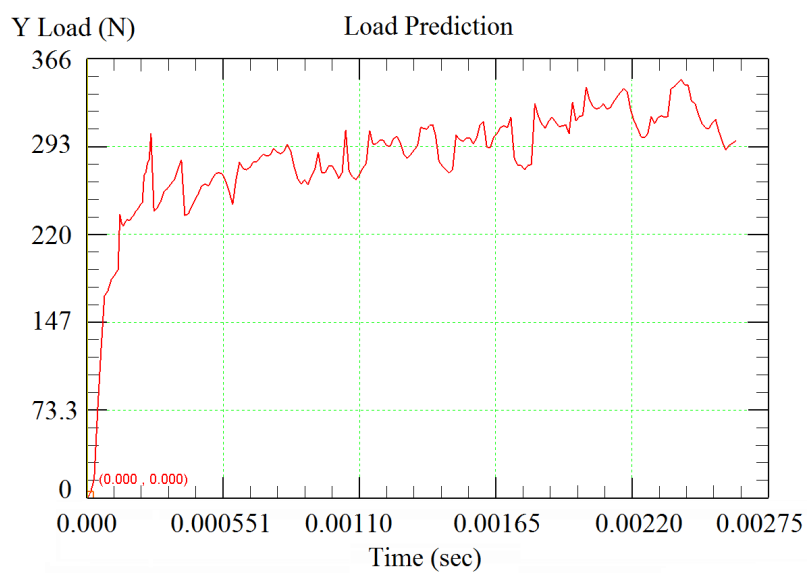

(b) Feeding cutting force

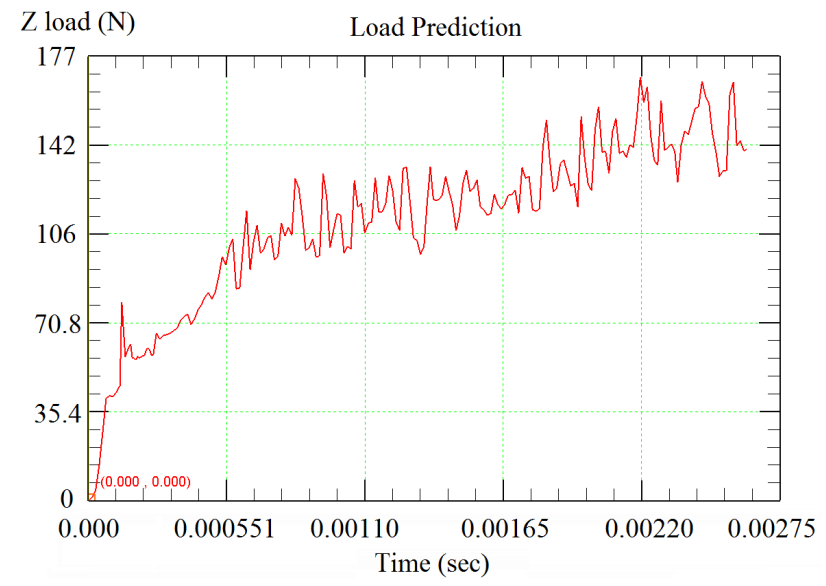

(b) Thrust cutting force

Fig. 4 Simulation of cutting force under different parameters

In order to discuss accuracy of the DEFORM-3D simulation in cutting process, cutting force experiments are carried out. The CNC lathe SK50P is used, its main parameters are as follows. Spindle rotation speed is from 62 to $1620 \mathrm{rpm}$, rated power is $7.5 \mathrm{KW}$, torque is $800 \mathrm{~N}$.m, maximum cutting length of $X$ and $Z$ directioni550 and $500 \mathrm{~mm}$ respectively, and so on. Cutting forces were measured by a Kistler 9265B three-piezoelectric dynamometer, the matching Kistler 5019A charge amplifier and the corresponding data acquisition and processing system. Its main parameters are as follows. Sensitivity is $0.05 \mathrm{~N}$, measuring range is within plus or minus $15 \mathrm{KN}(\mathrm{X}, \mathrm{Y}, \mathrm{Z})$, and stiffness is $1 \mu \mathrm{m} / \mathrm{KN}$. 
Results of simulate and experimental cutting force are shown as figure 5. From figure 5, we can find the simulate results are relatively close to experiment. With the increase of $a_{p}$, the upward trend of simulation is similar to experiment for cutting forces. This illustrates that DEFORM-3D can be used for simulation of cutting process for materials.

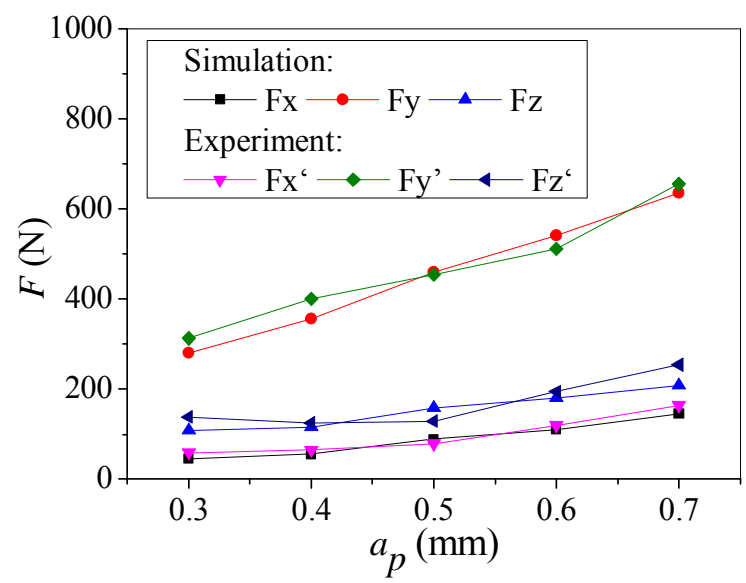

Fig. 5 Comparison of cutting force based on simulation and experiment

\section{Summary}

In this paper, software DEFORM-3D is used to simulate cutting process of materials in turning for TC3. And experiments of cutting force are carried out to validate. The results show that DEFORM-3D can simulate cutting process of materials and has good validity and accuracy.

\section{Corresponding Author}

Name: QIN Lu-fang, Email: 798033365@qq.com, Mobile phone: 13776787095

\section{Acknowledgments}

This work was supported by Funding of Jiangsu student' practice innovation training program (no. 201511998067X).

\section{References}

[1] Halil Bil, S Engin Kilic, A Erman Tekkaya, A comparison of orthogonal cutting data from experiments with three different finite element models, International Journal of Machine Tools \& Manufacture. 44 (2004) 933-944.

[2] F Klocke, S Hoppe, Simulation of the metal cutting process-reliability and optimization, International Journal of Production Engineering and Computers. 4 (2003) 43-52.

[3] H. B. Wu, S. J. Zhang, 3D FEM simulation of milling process for titanium alloy Ti6Al4V, The International Journal of Advanced Manufacturing Technology. 71 (2014) 1319-1326.

[4] Eckart Uhlmanna, Robert Gerstenbergera, Jörg Kuhnertb, Cutting Simulation with the Meshfree Finite Pointset Method, Procedia CIRP. 8(2013) 391-396.

[5] Domenico Umbrello, Finite element simulation of conventional and high speed machining of Ti6A14V alloy. Journal of materials processing technology. 96(2008) 79-87.

[6] Madalina CALAMAZ, Dominique COUPARD, Franck GIROT, A new material model for 2D numerical simulation of serrated chip formation when machining titanium alloy Ti-6Al-4V, Intemational Joumal of Machine Tools\&Manufacture. 48(2008) 275-288. 